\title{
Enabling Virtual Organization System for Agro Business
}

\author{
Adedoyin Odumabo \\ Computer Science Dept. \\ Lagos State University \\ Nigeria
}

\author{
David Ikudaisi \\ Computer Science Dept. \\ Lagos State University, \\ Nigeria
}

\author{
Akinlolu Adekotujo \\ Computer Science Dept. \\ Lagos State University, \\ Nigeria
}

\author{
Onala Sejiro \\ Computer Science Dept. \\ Lagos State University \\ Nigeria
}

\begin{abstract}
In the competitive market, a virtual organization represents a growing response to the need for fasting time-to-market, low-cost and rapid solutions to complex organizational problems. Today, one of the problems of establishing a business in Nigeria is the high-cost acquisition of a physical building for business operations. Also, during this COVID-19 pandemic period, many businesses were handicapped except those that operate online. Virtual organization permits organizations to utilize the abilities and capabilities of other people by eradicating barriers of time and space. This new technology began as a need to do businesses online in a global marketplace, full of innovative and faster operation; thereby eliminating the need for a physical location before starting a business. The project's objective is to develop and implement a Virtual Organization System for the Agro business. This work used the waterfall model and incremental model; it is a sequence of stages such that the output of each stage becomes the input of the next and need more of frequent update. The system was developed using PHP, JAVASCRIPT, CSS, and HTML as the programming languages and MYSQL as the Database Management system. The modules of the system program such as the main menu, buy form, rent page, properties page, contact us form, were tested and reviewed. When a business opportunity is distinguished, a need for planning and developing a virtual organization may be an opportunity idea to adopt in other to avoid the huge amount of money needed to get an outlet for business transactions.
\end{abstract}

\section{Keywords}

Virtual organization, agro business

\section{INTRODUCTION}

The fast evolution of information and global communication technologies has led to the creation of an entirely new organizational form, based predominantly on Internet technologies. This technological vehicle is currently reinforcing the expansion of many service provisions and inter-/intra- enterprise integration in all market sectors. The current business environment consists of many pressures to change such as the shortening of product development times and hence trying to create shorter and more efficient product cycles. Markets seem to become increasingly consumer-led, with insistent pressures to constantly bring down product costs and initiatives created to take full advantage of such innovative technologies.

Organizations are presently been confronted with exceptional challenges in an environment that is dynamic, complex, and frequently changing [1]. Economic activities are all changing to globalization [2]. With the swift development in Information and Communication Technology, effort in a distributed system has become faster, easier, and efficient. Over the last decade, new techniques for organizing businesses and the realization of new innovative business strategies have rocked management literature. Organizations look now towards completely new organizational arrangements to enable them to cope with these rapidly fluctuating conditions and pressures [3].

However, one of the methodologies that are receiving great attention in the literature is a virtual organization (VO). A Virtual Organization is a system whose memberships are physically apart, regularly working by a computer while performing with others as a solitary entity. Foster defined virtual organization as a set of participants or members with various relationships that wish to share resources to perform a task [4]. Resources include data, computers scientific instruments, software, etc. The coordination of these resources is very important because a set of resources that may be needed to accomplish a task and the existing resources may be changing as membership in the virtual organization is dynamic (i.e. members may join or leave at any time). It is a network of autonomous arrangements that are linked together, frequently momentarily, to produce a service or product. It is frequently connected with such languages as virtual offices, virtual teams, and virtual leadership [5]. Several very distinctive characteristics are evident in their description of virtual organizations, one such example being that they are "extremely focused, goal-driven, and powered by time-based competition". Virtual organizations use technology as the central form of communication, coordination, and are particularly useful in meeting the needs of rapid change. Therefore, there is an inherent element of both flexibility and synergy present within virtual organizations [6].

A business environment is a place where the customer meets with the business owner/worker(s) for a business transaction. One essential factor for business owners is a physical meeting point or location. However, an intended business owner needs to have a huge amount of money to secure a business environment which in turn reduces the rate of business growth in Nigeria. This new technology will give a business owner a viable option of Virtual Organization System in businesses even at this COVID 19 period that made physically run businesses handicapped. A virtual organization is based on information technologies that enable it to use resources and competences dispersed spatially, as well as share information and knowledge within the network created by the company and its stakeholders. Work in a virtual organization is performed outside the framework of time and place, taking the most common form of remote work (i.e. teleworking) as part of virtual work teams $[3,7]$.

Virtual organizations operating with lower costs are more competitive, faster to market, more innovative, have access to more capital and larger markets. The benefits of virtual organization systems are increases in employee productivity, morale, and commitment because time spent in commuting (traveling, hold-up, car repairs, etc.) is eliminated; decreases in sick leave; and improvements in the retention and recruitment of employees. It offers flexibility and the comfort of doing your work independently without following work 
rules, such as a dress code and traditional work hours [8]. Virtual work benefits the environment and society as fewer people are traveling in cars, buses, and trains, these reduce the number of vehicle emissions and decrease fuel usage. It prevents unnecessary and unwelcome interruptions by coworkers and managers that can hinder efficiency and concentration [9]. However, Virtual work requires selfdiscipline, self-motivation, and extra self-focus. Virtual best workers are individuals who are happy doing their work independently rather than those who need to have regular contact with others (e.g. Sanguine). Besides, some occupations such as laborers and clinicians are unsuitable for a virtual worker. However, positions that require minimal personal interaction may be very well suited for virtual workers. Also, the managers who supervise virtual work must be comfortable with it and accept huge responsibility. The taxonomy of collaborative organizations brings about the complexity of possible using non-conventional VO structures for areas such as supply chain and virtual alliances [10].

The project's objective is to develop and implement Virtual Organization System for Business owners especially Agro business. This work is structured as follows: Section 2 presents the materials and methods while Section 3 presents the results of the system. Discuss is explained in section 4 and Conclusion and future work is presented in Section 5.

\section{MATERIALS AND METHODS}

\subsection{System Description}

This is a web-based system that is limited to only sales and rent of farm tractors, farmers can order their preferred product online and will be delivered at their desired location. This system also can allow for the plug-in of an online payment module. The UML shows how customers interact with the system while the admin at the other end receives any information stored by the system and also does the updating of products (see Fig 1).

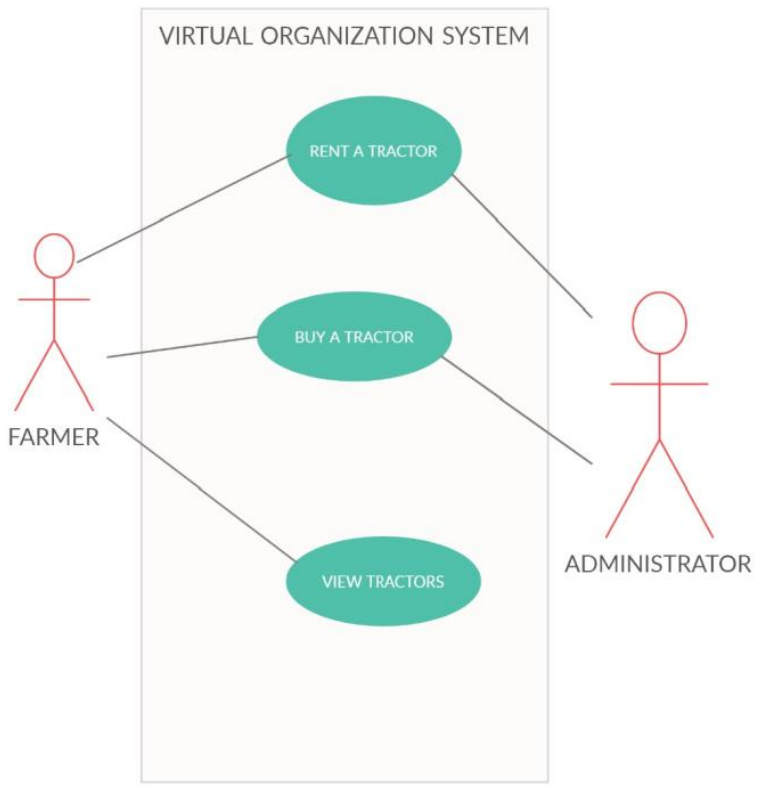

Fig 1: Use Case of Virtual Organization
The following requirements were captured for the intended use of the system.

Check tractor model: Allow customers to check the available tractors, their details and price for sale/rent.

Rent a tractor: System allow customer to make request to rent a tractor. It takes detail like names, phone number, farm address, home address, tractor model, delivery point etc.

Buy a tractor: System allow customer to make request to buy a tractor. It takes detail like names, phone number, farm address, home address, tractor model, delivery point etc.

Send Comment: It enable customers to send comment on service rendered to them.

\subsection{System Implementation}

This work used the waterfall model and incremental model; it is a sequence of stages such that the output of each stage becomes the input of the next and need more of frequent update. In the development of this system many technologies were used which are suitable for the application software. HTML, CSS, JQUERY, JAVASCRIPT, PHP were used for the front end and MySQL was used to develop the database (back end)

\section{RESULTS}

\subsection{System Testing and Validation}

System testing and validation are the most important steps after the implementation of the developed system. The system testing is performed to confirm that there were undiscovered errors in the implemented system. The software will be executed several times in order to find out any possible errors in the different modules of the system. The primary concern is the compatibility of individual modules. The system review dealt with unforeseen problems that may arise during the operation and to guarantee that the system is able to cope with changes in the process of product ordering. 
The function of the program module is described below;

i. Main Menu: This displays the program menu; it guides the user on what to do and how to go about it at a particular time (see Fig 2).

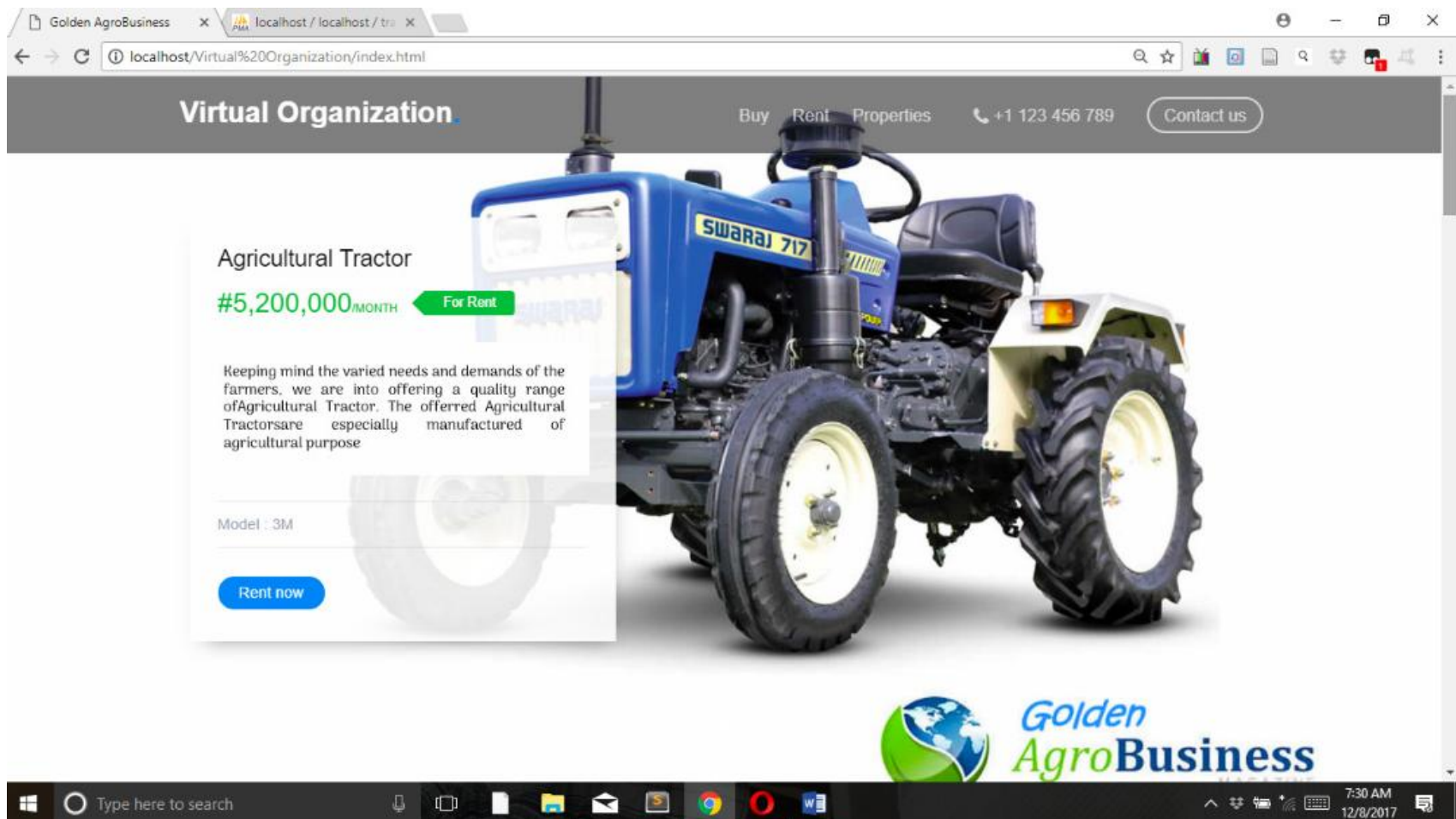

Fig 2: Main menu of the Virtual Organization

ii. Rent page: This allows customers/farmer to request for tractor use for a period of time (see Fig 3).

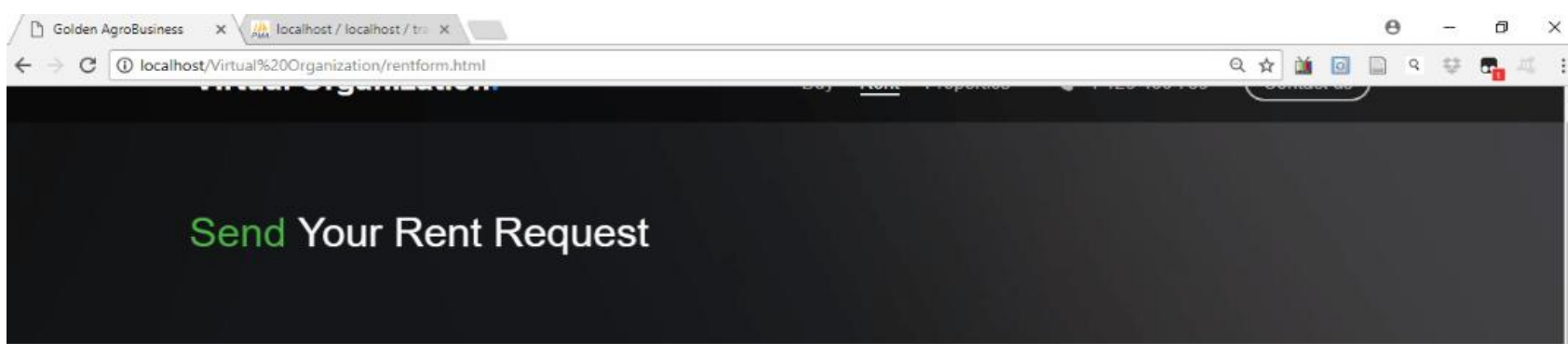

Our Rent Service

* Please all rent request should be a month ahead. Thank you

Your Name

Your Farm Address

Your Home Address

Your Mobile Number

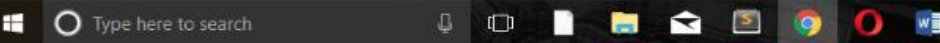

Fig 3: Renting page of the Virtual Organization 
iii. Properties page: This allow customers/farmers to have a view of all tractors for sales/rent (see Fig 4).

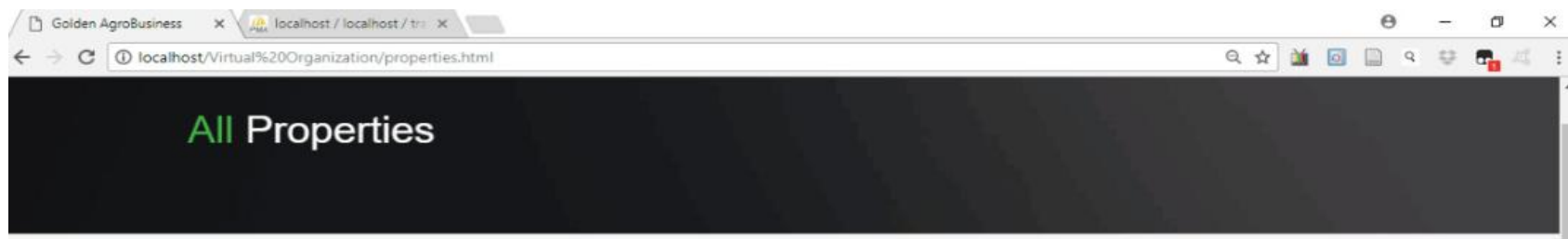

\section{Our Properties}

With sincere intentions to preserve and uplift our reputation in the market, we are dealers of a comprehensive variety of Tractor

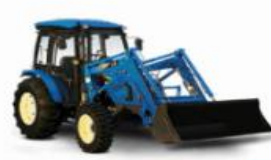

For Sale

110HP Farm Tractor

$\# 34,400,000$

Type: Wheel Tractor Usage: Farm

Model : K200L

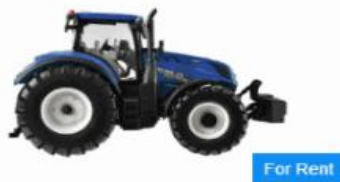

110HP 4 Wheel Drive Agriculture Farm Tractor

\#342,400 mosrth

Type: Wheel Tractor Usage: Farm

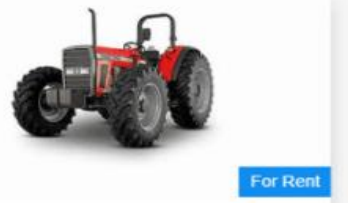

Waw 35HP Farm Tractor \#300,000 монтн Type: Wheel Tractor Usage: Farm
Tractor Certification: ISO, CE, EPA, CCC Model : T200P

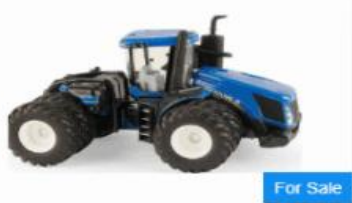

55HP Farm Tractor Wheel

\#20,000,000

Type: Wheel Tractor Usage: Farm

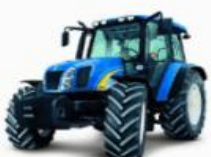

For Sale

130HP 4WD Large Farm Tracto $\# 50,000,000$

Type: Wheel Tractor Usage: Farm
Tractor Certification: ISO, CE, EPA, CCC.

Model :ML100

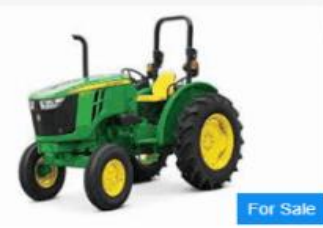

55HP Farm Tractor Wheel

\#20,000,000

Type: Wheel Tractor Usage: Farm

\section{Fig 4: Tractor Available page on the Virtual Organization System}

iv. Buy Form: This allows the customers/farmer to make request for purchase of tractor (see Fig 5).

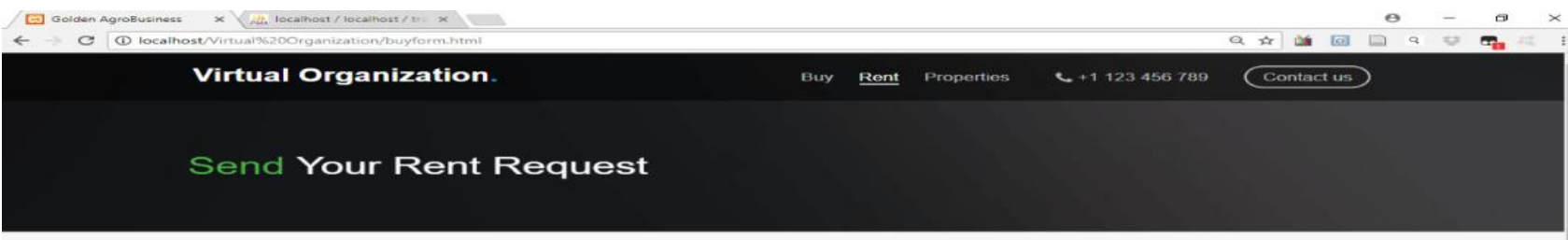


v. Contact us form: This allow the customers to send message about product (see Fig 6).
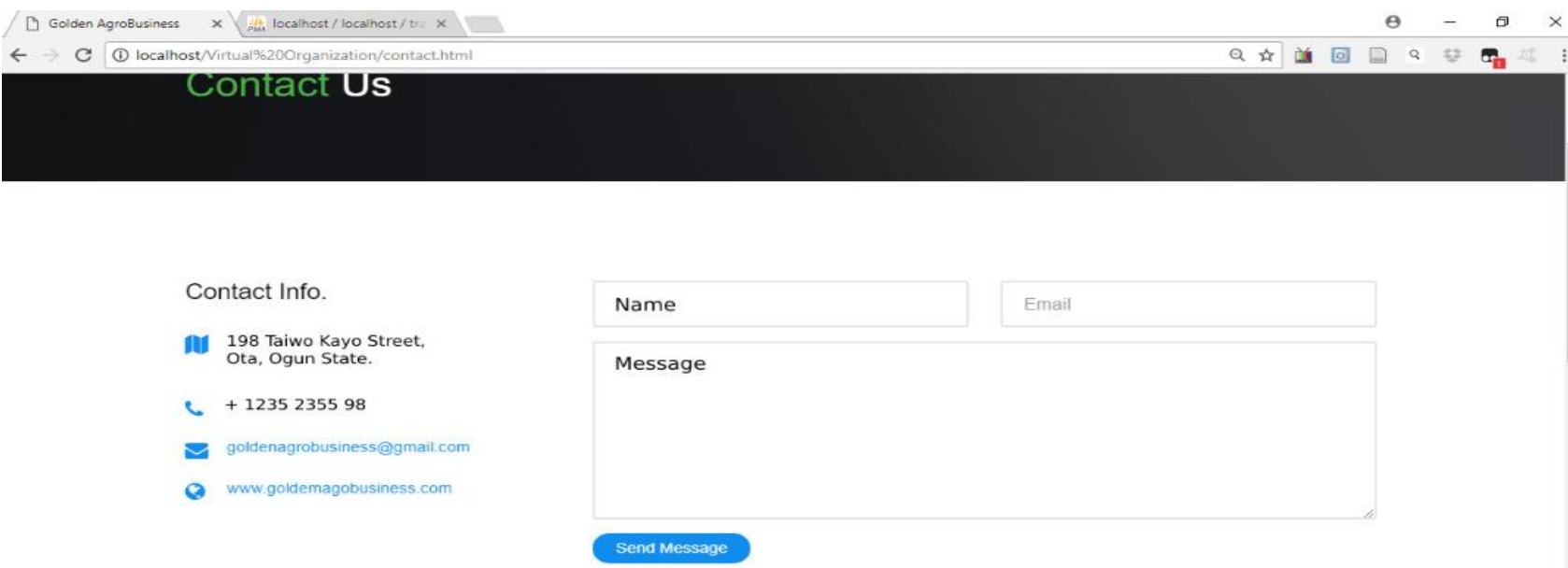

Fig 6: Contact form for Virtual Organization

\section{DISCUSSION}

The digitization of information is fundamentally changing the way work is done and value is created. Presently, significant human interactions are mediated through information technology. Today, information technology, particularly the internet has emerged as the source of a competitive advantage which no business organization can ignore except at a very high cost. One major contribution of ICT is the introduction of Virtual Organization. A virtual organization is an autonomous, globally distributed system about organizations, groups, or individuals, which/who without time or space hindrances, communicate through ICT while reaching a common goal.

There were many established virtual organizations especially for farmers where people can invest their money or purchase farm products easily online. Among such is Virtual Africa (www.virtualafrica.net), virtual farmers market (www.globalinnovationexchange.org), Agricultural investment platform (www.geoffery-agrofarming.business.net), $\quad$ Farmcrowdy (www.farmercrowdy.com), etc. We compared existed virtual organization systems; there is none for renting and buying of agricultural tractors.

\section{CONCLUSSION/FURTHER RESEARCH}

An organization is said to be virtual in the sense that it has little of any physical presence and relies on telecommunications and the Internet. It tends to be agile, flexible, and fluid. Virtual organization permits organizations to utilize the abilities and capabilities of other people by eradicating barriers of time and space. This new technology began as a need to do business online in a global marketplace, full of innovative and faster operation; thereby eliminating the need for a physical location before starting a business. When a business opportunity is distinguished, a need for planning and developing a virtual organization may be an opportunity idea to adopt in other to avoid the huge amount of money needed to get an outlet for business transactions.
This project is limited to only renting and buying of agrobusiness equipment. This system can handle the issue of online payment as plug-in and other services but chose to limit these services to equipment renting in this research work. In further research, this project can feature buyers of farm products and other relevant services can be added to this project.

\section{RECOMMENDATION}

The Virtual Organization is easy to use and friendly; this system will be useful in boosting the economy. Therefore, encourage businesses to employ virtual organization systems. Also, farmers can easily have access to tractors to use for a short period without the need to purchase any.

\section{CONFLICTS OF INTEREST}

The authors do not have any conflicts of interest.

\section{REFERENCES}

[1] I. Rezgui, C. Ciurea, and M. Doinea, "Collaborative virtual organizations in knowledge-based economy" Informatica Economica, vol. 16, pp. 143-154, 2012.

[2] T. Christe, N. J. Foss, and R. E. Levary, "The micro foundations movement in strategy and organization theory," The Academy of Management Annals vol. 9, pp. 575-632 2015.

[3] N. U. Ahmed, R. V. Montagno, and S. K. Sharma, "Strategy and Structure in a Virtual Organization," International Journal of E-Adoption vol. 2, pp. 48-60, 2010 .

[4] I. Foster, C. A. Kesselman, and S. Tuecke, "the Anatomy of the Grid: Enabling Scalable Virtual Organisations," International Journal of High Performance Computing Applications, vol. 15, pp. 200-222, 2001.

[5] W. F. Cascio and S. Shurygailo, " E-Leadership and Virtual Teams " Organizational Dynamics, vol. 31, pp. 362-376, 2003.

[6] M. K. Govareshki, S. J. Hosseini, and R. Taghinejad, 
"Use of knowledge maps in collaborative networks management (Case Study: SSFR Company)," International Journal of Computer Science and Network Security, vol. 17, pp. 21-28, September 2017.

[7] L. M. Camarinha-Matos, H. Afsarmanesh, N. Galeano, and A. Molina, "Collaborative networked organizationsConcepts and practice in manufacturing enterprises" Computers \& Industrial Engineering, vol. 57, pp. 46-60, 2009.

[8] M. Radovic-Markovic, "Virtual organizations: Employee competency and managerial issues." Annals of the University of Petrosani Economics vol. 14, pp. 287-290,
2014.

[9] R. Mayhew, "What Are the Advantages \& Disadvantages of Virtual Offices and Telecommuting?," Ed.

[10] N. Cheikhrouhou, A. H. Tawil, and A. Choudhary, "Modelling competence-based virtual organizations using the unified enterprise competence modelling language," International Journal of Production Research, vol. 51, pp. 2138-2159, 2013.

[11] N. Hoppen, A. d. C. Z. Klein, and E. H. Rigoni, "Sociomaterial practices: challenges in developing a virtual business community platform in agriculture," BAR-Brazilian Administration Review, vol. 14, 2017. 